\title{
TRADE-OFF PARA ALTERNATIVA DE FUNDAÇÃO PARA UMA TORRE DE PRÉ-CALCINAÇÃO DE CLÍNQUER
}

\section{ARTIGO ORIGINAL}

CASTRO, Maria Elisa de Lima ${ }^{1}$

NOVAIS, Tiago de Morais Faria ${ }^{2}$

CASTRO, Maria Elisa de Lima. NOVAIS, Tiago de Morais Faria. Trade-off para alternativa de fundação para uma torre de pré-calcinação de clínquer. Revista Científica Multidisciplinar Núcleo do Conhecimento. Ano 04, Ed. 10, Vol. 09, pp. 86101. Outubro de 2019. ISSN: 2448-0959, Link de acesso: https://www.nucleodoconhecimento.com.br/engenharia-civil/alternativa-defundacao

\section{RESUMO}

Todas as cargas de uma estrutura são transmitidas ao solo através da fundação, em um sistema denominado de interação solo-estrutura. A fundação é dimensionada de acordo com as cargas atuantes e também de acordo com estudos geotécnicos para definição do tipo de solo e resistência. O dimensionamento de mais de um tipo de fundação para esta estrutura é importante para analisar e definir a que tiver o melhor custo benefício, sendo significativo o desenvolvimento de um trade-off. O presente estudo de caso foi desenvolvido para uma torre de pré-calcinação de clínquer de uma fábrica cimenteira do oeste do estado de Minas Gerais, Brasil. Foram feitas as análises do solo, do cálculo de três tipos de fundação por três métodos de dimensionamento, realizando-se um trade-off para a verificar os pontos positivos e negativos de cada um para a definição de qual o tipo mais adequado.

\footnotetext{
${ }^{1}$ Acadêmica do $10^{\circ}$ período do curso de Engenharia Civil.

2 Graduação, Mestrado e Doutorado em Engenharia Civil.
} 
Palavras Chave: Trade-off, fundação, interação solo-estrutura.

\section{INTRODUÇÃO}

A escolha pela técnica e/ou os materiais a serem utilizados na execução de fundações para edificações deve ser determinada pelas características da edificação em questão, bem como dos parâmetros obtidos na investigação do solo, informações que, mesmo com satisfatório grau de precisão em sua execução, carecem de princípios subjetivos, próprios do engenheiro projetista. $\mathrm{O}$ trade-off caracteriza-se como uma alternativa de interesse significativo nesta situação, visando a otimização da aplicação de recursos em projetos desta natureza e culminando em projetos melhores para edificações residenciais, comerciais e industriais, sendo este último de maior complexidade, tendo em vista o maior número de variáveis que a envolvem.

De acordo com Santos João (2014), a etapa inicial da fase de concepção de um projeto industrial é a identificação dos requisitos da edificação. Estes requisitos podem ser econômicos, operacionais e estruturais. Destacando este último, sabendo que a ocupação das indústrias pode ser variada, as estruturas precisam sustentar operações, equipamentos e as próprias instalações. Os levantamentos geotécnicos tornam-se primordiais neste ponto para o fornecimento de dados importantes para o dimensionamento e para a construção. Para Nangan II et al. (2017), os edifícios podem se movimentar, sendo a causa fundamental do movimento em edifícios geralmente associada a um ou mais problemas no solo da fundação. A operação do forno rotativo em uma fábrica cimenteira, por exemplo, é essencial para a produção, portanto, deve-se levar em conta o alinhamento de seu eixo no primeiro piso da torre de pré-calcinação. Este fato irá demandar análises do solo, da estrutura da torre e de considerações de recalques no dimensionamento da fundação da estrutura de apoio do forno para evitar movimentações do edifício, ou seja, evitar recalques não previstos. Conforme Barbosa e Conciani (2016) em ambientes industriais, quando ocorre esse tipo de patologia, as soluções têm limitações de funcionamento da fábrica, além da limitação de espaço para manobras e de altura para equipamentos, impondo 
severas restrições às possíveis soluções. Os recalques podem ser evitados ou minimizados por uma adequada interpretação e caracterização do solo.

Conforme Velloso e Lopes (2010), frequentemente as estacas trabalham em grupo, o qual é formado pela ligação estrutural no topo, chamado bloco de coroamento. Nessa condição, a capacidade de cargas e os recalques do grupo são diferentes do comportamento de uma estaca isolada, devido à interação entre as estacas próximas através do solo que as circunda. Essa interação é chamada de efeito de grupo. A primeira abordagem sobre este efeito foi feita por Terzaghi e Peck (1948) através do radier fictício, imaginando uma fundação direta acima das estacas, objetivando calcular o acréscimo de tensões em camadas compressíveis abaixo da ponta das estacas para determinação convencional de recalques. Albuquerque e Gusmão (2006), abordam que o desempenho da edificação é conduzido pela interação soloestrutura e que o processo é iniciado na fase de construção e continua até que alcance um estado de equilíbrio, em que as tensões e as deformações estão estabilizadas, tanto da estrutura como dos maciços do solo.

Segundo Matirosyan e Sobolev (2016) para garantir segurança e confiabilidade, são indispensáveis os itens como as condições geológicas/geotécnicas, as quais devem levar em consideração o comportamento dos solos com efeitos dinâmicos para estudo das propriedades, prever tensão-deformação do solo das estruturas projetadas, edifícios e instalações próximas, realizar análises em laboratório das amostras coletadas em campo e levar em conta a interação solo-estrutura. É fundamental também verificar se há influência de vibrações, como por exemplo o moinho de coque de petróleo, equipamento que se situa próximo à torre, verificar se é necessário ou não a consideração da carga do vento, e outras diversas interferências que vão surgindo ao decorrer dos cálculos. O dimensionamento estrutural é de extrema importância, inclusive se tratando de grandes estruturas, como as que compõem obras de áreas industriais, as quais estão sujeitas a carregamentos peculiares, sendo um ponto de atenção para as devidas considerações, incluindo todos os equipamentos e superestrutura que dissiparão suas cargas no solo através da fundação. Como toda edificação, esses ambientes também são suscetíveis a 
problemas como recalques, quando não dimensionada corretamente a fundação, ou até mesmo o superdimensionamento, com o intuito de deixá-las mais seguras, mas o superdimensionamento nem sempre proverá este resultado, além do alto custo.

Segundo Moreira (2017), tendo em vista minimizar o custo e prazo de implantação e maximizar qualidade e segurança na construção de torres de pré-calcinação de indústrias cimenteiras, o planejamento se faz presente em todas as etapas, da atividade de montagem/desmontagem da forma deslizante para deslizamento da superestrutura em concreto armado ao mapeamento das redes elétricas, rede de dados, água e esgoto antes de qualquer atividade de escavação, evitando que a máquina atinja a rede sob o solo, almejando maior assertividade em projetos executivos, afim de evitar retrabalhos de engenharia. Neste trabalho será desenvolvido o trade-off para analisar a melhor alternativa entre três tipos de fundação que serão dimensionados - hélice contínua, trado mecânico e Strauss - através dos métodos Aoki e Velloso (1975), Décourt e Quaresma (1978) e Teixeira (1996), para a fundação da torre de pré-calcinação de clínquer de uma fábrica cimenteira localizada no oeste de Minas Gerais, Brasil, fazendo um comparativo entre capacidade de carga das estacas, volume de concreto e volume de escavação, objetivando o êxito da obra.

\section{MATERIAIS E MÉTODOS}

O estudo de caso em questão é caracterizado por uma torre de pré-calcinação de clínquer de uma indústria cimenteira do oeste do estado de Minas Gerais, Brasil. Este estudo tem como objetivo principal a elaboração de um trade-off da fundação desta estrutura, analisando a que terá o melhor custo benefício, que poderá ser caracterizado pelo volume de serviços para sua realização e o aproveitamento das peças estruturais da fundação.

Os métodos utilizados no dimensionamento das fundações neste estudo caracterizam-se como métodos semiempíricos, sendo eles Aoki e Velloso (1975), Décourt e Quaresma (1978) e Teixeira (1996). Os referidos métodos foram escolhidos para a realização deste estudo por apresentarem-se como os mais comumente 
citados nas referências bibliográficas de geotecnia e por possibilitarem o dimensionamento dos elementos estruturais de fundações apenas com informações obtidas em Ensaios de Sondagem à Percussão - SPT. Características como simplicidade e robustez, aliado ao seu baixo custo e a experiência empírica acumulada na execução e na aplicação dos resultados, tornam esta sondagem uma ferramenta indispensável à prática de engenharia (LOBO, 2005).

No local de implantação da torre de pré-calcinação, foram realizados quatro furos de sondagem apresentado na FIG. 1. A área projetada da edificação é de aproximadamente $800 \mathrm{~m}^{2}$, sendo a quantidade de furos adequada à NBR 8036 (ABNT, 1983), a qual menciona que para edifícios com área projetada em planta de até $1.200 \mathrm{~m}^{2}$, deve-se ter um ponto de investigação a cada $200 \mathrm{~m}^{2}$. A profundidade dos furos das amostras coletadas foi na média de 21 metros. Estes dados foram disponibilizados pela empresa para o desenvolvimento deste trabalho através de relatórios de sondagem e desenhos de referência da torre em questão.

Figura - Furos de sondagem (SPT-F01 a SPT-F-04) no local de implantação da torre de pré-calcinação.

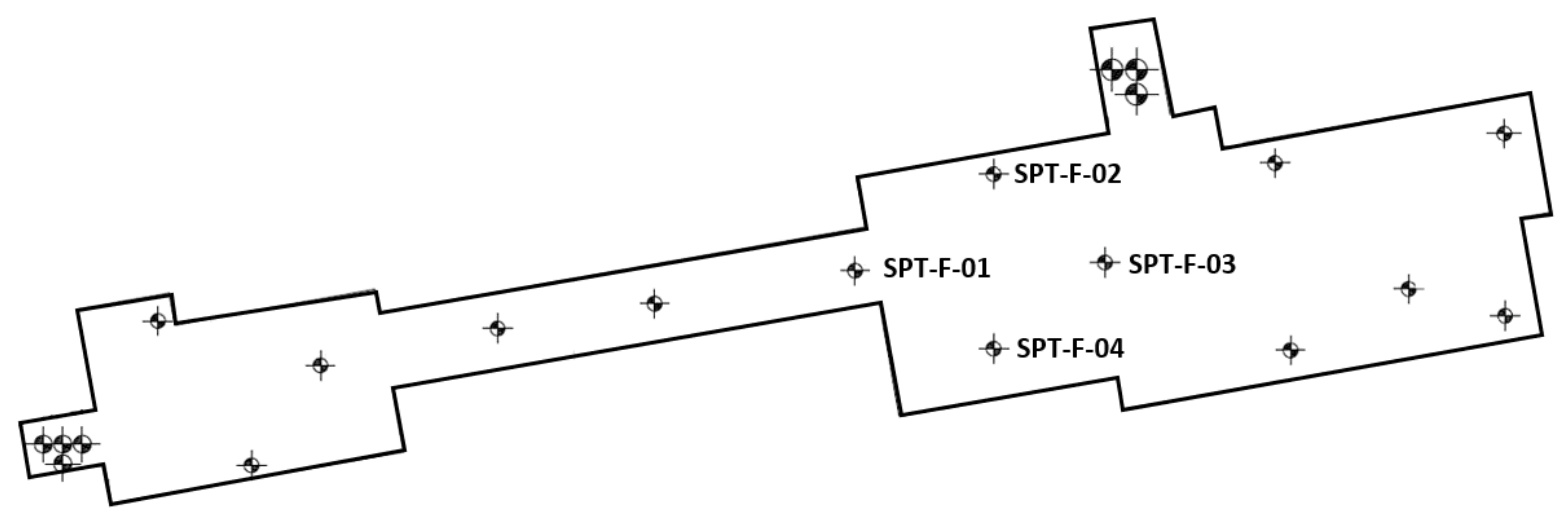

Fonte: Documento fornecido pela empresa adaptado pelo autor, 2019.

O forno rotativo está posicionado no primeiro piso da torre de pré-calcinação, conforme indicado na FIG. 2, tendo como ponto de atenção mantê-los alinhados, 
dispondo de uma análise mais cuidadosa do projeto de fundações, afim de evitar recalques não previstos.

Figura - Forno rotativo posicionado na torre de pré-calcinação: vista lateral.

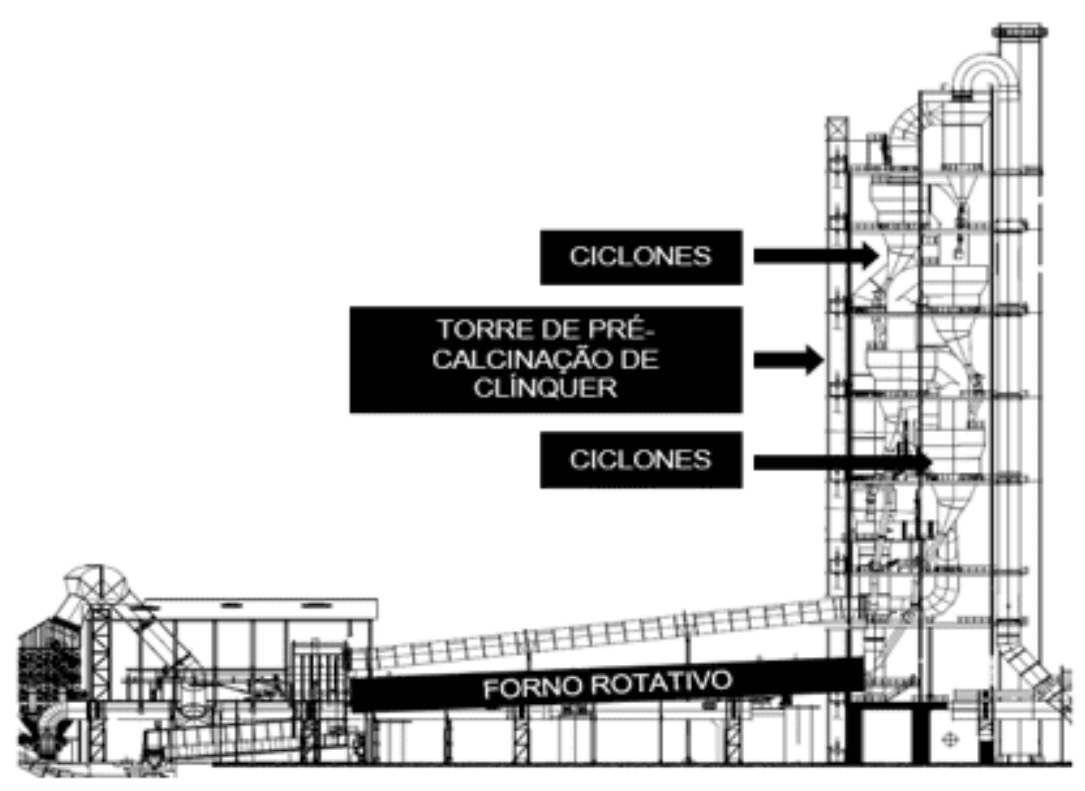

Fonte: Documentação técnica fornecida pela empresa adaptada pelo autor, 2019.

A referida torre possui seis estágios de altura, totalizando 116 metros e carga total de $355.434 \mathrm{kN}$, resultante dos equipamentos como os ciclones, calcinador, duto de ar terciário, entre outros, e também da estrutura em concreto armado e pisos em estrutura metálica, de acordo com os dados da TAB. 1 a seguir.

Tabela - Cargas atuantes na torre de pré-calcinação de clínquer.

CARGAS ATUANTES NA TORRE DE PRÉ-CALCINAÇÃO DE CLÍNQUER

\begin{tabular}{|l|l|}
\hline Equipamentos sobre a torre & Peso (kN) \\
\hline Ciclones & 69.290 \\
\hline Calcinador & 12.195 \\
\hline Duto de ar terciário & 3.578 \\
\hline Câmara de combustão & 2.751 \\
\hline
\end{tabular}

Disponível em: https://www.nucleodoconhecimento.com.br/engenharia-civil/alternativa-defundacao 


\begin{tabular}{|l|l|}
\hline Câmara de entrada & 1.190 \\
\hline Alimentação de moagem & 1.938 \\
\hline Dutos de material moído & 2.545 \\
\hline Duto downcomer & 3.188 \\
\hline Duto de gás quente & 536 \\
\hline Outros equipamentos & 1.372 \\
\hline Total & 98.583 \\
\hline Outras cargas da torre & Peso (kN) \\
\hline Prédio & 168.752 \\
\hline Estrutura de aço & 17.114 \\
\hline Carga de tráfego & 70.985 \\
\hline Total & 256.851 \\
\hline Carga total & 355.434 \\
\hline
\end{tabular}

Fonte: Documento fornecido pela empresa adaptado pelo autor, 2019.

Para o dimensionamento da fundação do estudo de caso, definiu-se um bloco de coroamento para travamento das estacas, fazendo com que toda a carga da torre de pré-calcinação fosse descarregada neste bloco em uma interação de efeito de grupo. As cargas obtidas para o dimensionamento foi o somatório de todas as cargas atuantes na torre, diferente da maioria dos cálculos que consideram o carregamento atuante em cada pilar. De acordo com Santos Filho et al. (2000), o sistema de transferência de carga, assim como a distribuição de recalque dentro de um grupo de estacas, abrange um mecanismo de interação de estacas, bloco de estacas e o solo. A análise é realizada com a relação de tensão-deformação e características de ruptura de todos os elementos do sistema, o qual tende a suportar mudanças induzidas pelas interações das estacas. A relação de carga-recalque de um grupo de estacas é afetada pela natureza do carregamento, as propriedades do solo, a instalação da estaca, a geometria e a interação de efeito de grupo.

Conforme o dimensionamento em um único bloco de coroamento, foi feita uma média das resistências apresentadas nas quatro amostras para obter um tipo de estaca mais

Disponível em: https://www.nucleodoconhecimento.com.br/engenharia-civil/alternativa-defundacao 
adequada para o bloco, estabelecendo uma profundidade como padrão para o dimensionamento dos três tipos de fundação levados em conta no estudo de caso. Cada tipo de estaca tem um diâmetro diferente, pois foi considerado o padrão comercial e o maior diâmetro das estacas do tipo hélice contínua, trado mecânico e Strauss, os quais são respectivamente, 100, 50 e 45 centímetros. Diante disso, foi possível obter os diferentes dimensionamentos da fundação para a torre, três opções que se diferem pelo tipo proposto, correspondendo a hélice contínua, trado mecânico e Strauss, e pelo diâmetro da estaca, mantendo apenas a profundidade padrão e o limite da dimensão do bloco de coroamento, para a possível análise do custo benefício entre elas, comparando a capacidade de carga das estacas, volume de concreto e volume de escavação.

\section{RESULTADOS E DISCUSSÕES}

Em uma análise geral dos relatórios de sondagem dos furos realizados, observa-se a predominância de solo do tipo argila silto arenosa, conforme apresentado na TAB. 2, não havendo presença de água em nenhum deles. Sabendo-se do tipo de solo que deverá suportar as cargas da torre, a elaboração e dimensionamento do projeto fica mais preciso e seguro, evitando retrabalhos imediatos de engenharia.

Tabela - Síntese do SPT, sinalizando a predominância de solo do tipo argila silto arenosa.

\begin{tabular}{|c|c|c|}
\hline 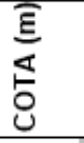 & 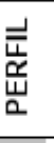 & DESCRIÇÄO \\
\hline 3,00 & & Argila silto arenosa rija \\
\hline 6,85 & & Argila silto arenosa mole a média \\
\hline 8,45 & & Argila silto arenosa mole \\
\hline 9,00 & & Silte argilo arenoso rijo \\
\hline 11,67 & & Silte argilo arenoso médio \\
\hline 12,78 & & Argila silto arenosa mole \\
\hline 15,00 & & Argila silto arenosa média a rija \\
\hline 16,90 & & Argila silto arenosa rija a dura \\
\hline 21,00 & & Argila silto arenosa dura \\
\hline
\end{tabular}

Fonte: O autor, 2019.

Disponível em: https://www.nucleodoconhecimento.com.br/engenharia-civil/alternativa-defundacao 
Fez-se o intermédio entre os quatro furos de sondagem, obtendo uma média, apresentada no GRÁF. 1. Esta média foi a utilizada para as considerações do tipo de solo e de resistência em todos os cálculos para o dimensionamento da fundação. $O$ marco inicial para qualquer tipo de obra deve ser a análise do solo, pois é o local de apoio, onde deverá suportar as cargas da edificação.

Gráfico - Média da resistência do solo dos furos de sondagem para determinar a resistência do solo a ser utilizada e profundidade da fundação.

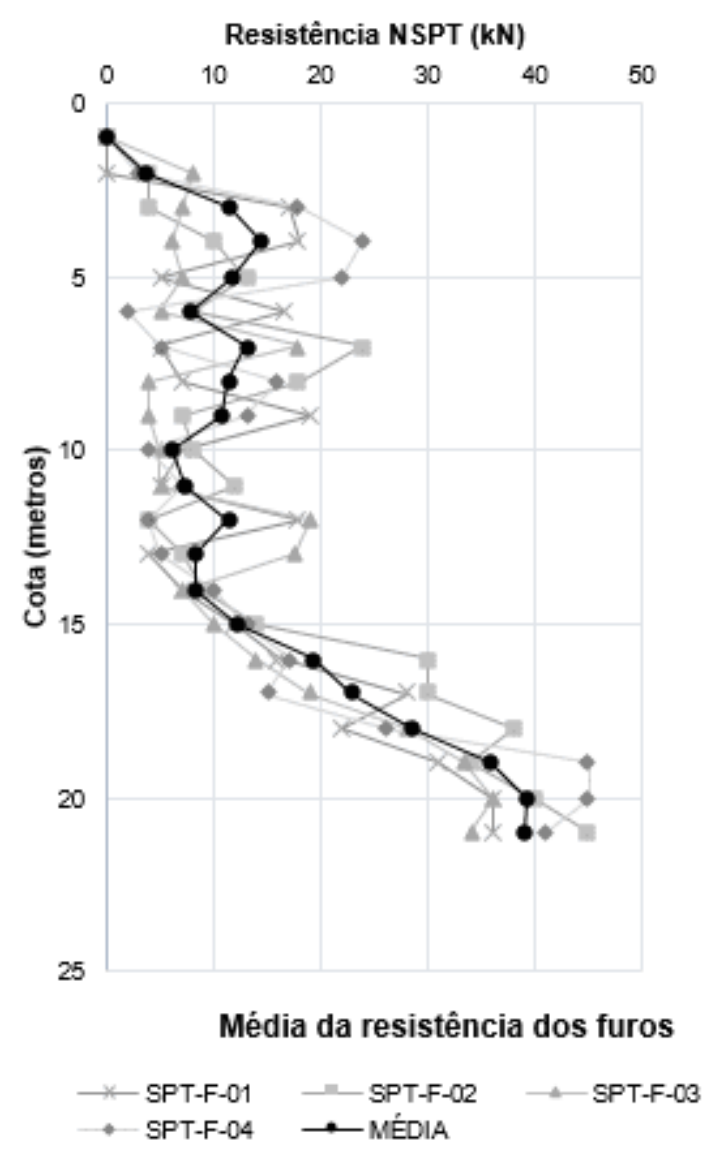

Fonte: O autor, 2019.

Nota-se que o solo do local de implantação da torre atinge uma resistência maior a partir de aproximadamente 16 metros, portanto, para maior segurança e para que a ponta da estaca fique apoiada em um solo com uma resistência maior, considerou-se 
uma profundidade de 19 metros. Essa profundidade foi definida para os três tipos de fundação dimensionados, para a realização da comparação.

Teve-se como resultado as cargas apresentadas na TAB. 3. No caso de visar um projeto de fundação utilizando apenas um método, deve-se utilizar o que apresentar a menor carga admissível, adotando neste estudo de caso, por exemplo, o método de Aoki e Velloso.

Tabela - Resultados para o dimensionamento dos três tipos de fundação pelos três métodos propostos, para suportar a carga de $355.434 \mathrm{kN}$ da torre de pré-calcinação.

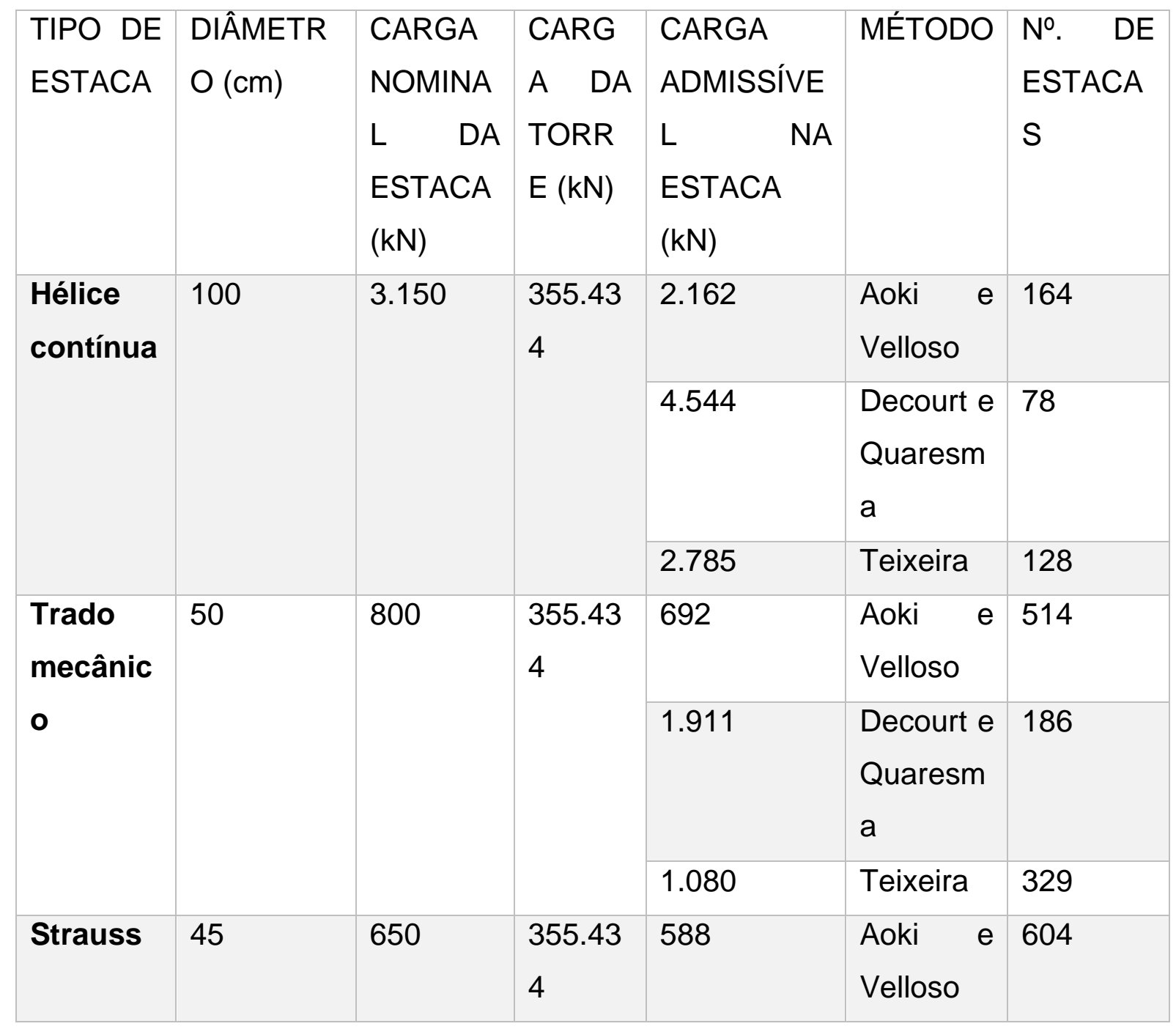




\begin{tabular}{l|l|l}
1.688 & $\begin{array}{l}\text { Decourt e } \\
\text { Quaresm } \\
\text { a }\end{array}$ & 211 \\
945 & Teixeira & 376
\end{tabular}

Fonte: O autor, 2019.

No estudo de caso, não foi visado nenhum método de dimensionamento de fundações em específico, mas a média entre os três métodos para alcançar um resultado mais preciso e seguro, evitando o superdimensionamento da estrutura e buscando o sucesso da obra, pois o que apresenta a menor carga pode acabar inviabilizando o projeto em termos de custo pela maior quantidade de estacas. Portanto, obteve-se os resultados apresentados na TAB. 4 a seguir.

Tabela - Resultado mediano de número de estacas.

\section{TIPO DE ESTACA MÉDIA №. DE ESTACAS}

\begin{tabular}{|l|l|}
\hline Hélice contínua & 123 \\
\hline Trado mecânico & 343 \\
\hline Strauss & 397
\end{tabular}

Fonte: O autor, 2019.

É perceptível a disparidade do número de estacas entre cada método e em cada tipo de fundação. Essa diferença é devido às considerações e parâmetros distintos de cada um, como por exemplo, o coeficiente de segurança e fatores de conversão no Aoki Velloso para utilizar a sondagem do tipo SPT. Outro fator é a diferença do diâmetro das estacas, pois a que tem o maior diâmetro, o qual é o dobro dos outros, consequentemente tem uma menor quantidade de estacas no bloco de coroamento. $\mathrm{E}$ também às características para execução, a hélice contínua tem uma limitação menor, pode ser executada caso exista presença de lençol freático, sendo os matacões sua principal limitação. Já as estacas do tipo trado mecânico e Strauss 
apresentam maiores restrições como solo muito mole ou presença de água, além de um baixo desempenho quando se trata de quantidades grandes de estacas.

A partir dos números de estacas obtidos pelos resultados medianos, fez-se a elaboração das plantas de fundação na área delimitada para execução do bloco de coroamento de 38 metros de comprimento por 29 metros de largura. Na FIG. 3, temse a planta de fundação da estaca tipo hélice contínua, totalizando 125 estacas com 19 metros de profundidade e um metro de diâmetro. Para as estacas escavadas, recomenda-se que o distanciamento entre eixos seja de três vezes o diâmetro nominal da estaca, portanto, para esta estaca, teve-se um distanciamento de três metros, apresentando a distribuição de forma equilibrada e em todo o limite do bloco de coroamento.

Figura 3 - Planta de fundação da estaca do tipo hélice contínua.

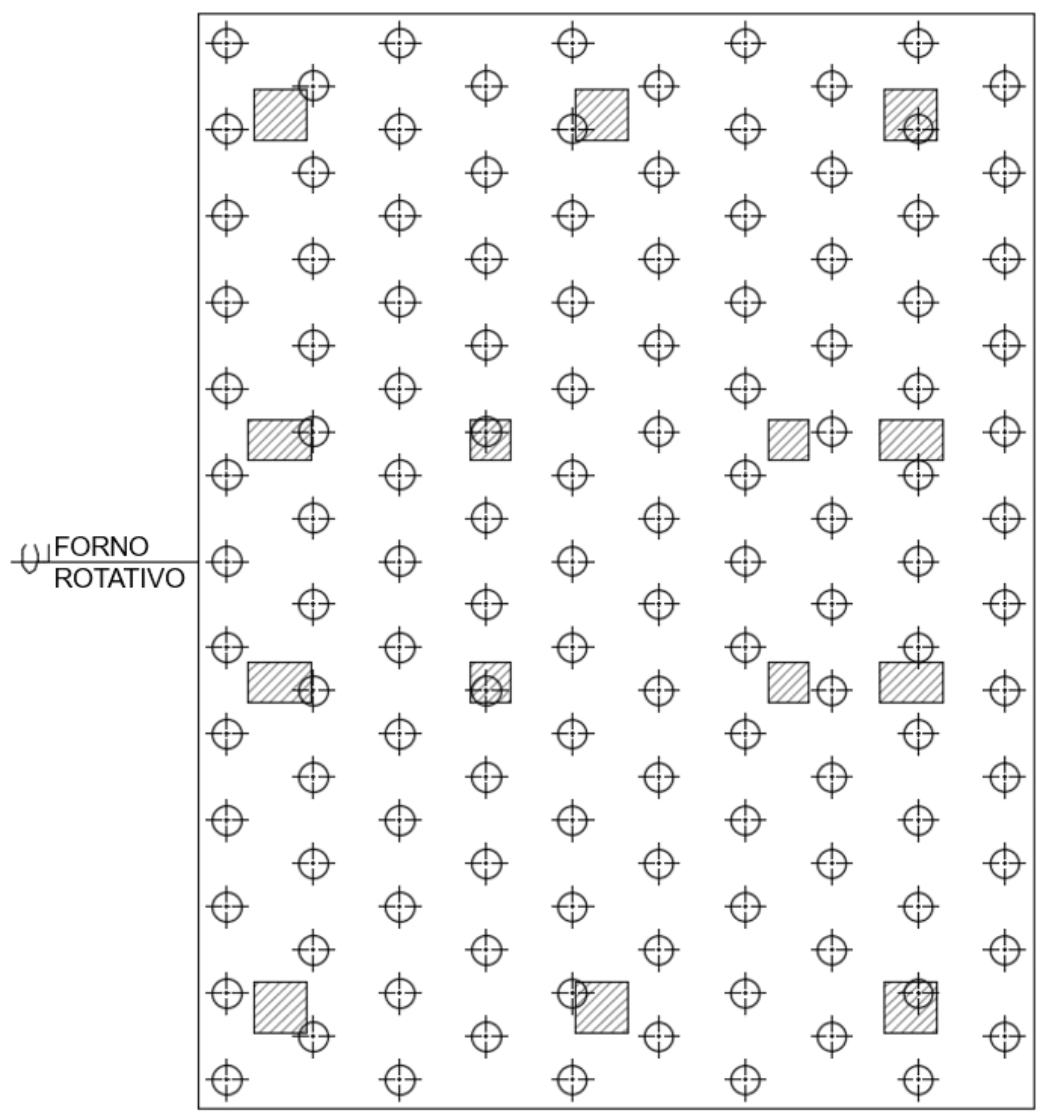

Fonte: O autor, 2019.

Disponível em: https://www.nucleodoconhecimento.com.br/engenharia-civil/alternativa-defundacao 
A estaca do tipo trado mecânico é apresentada na planta de fundação da FIG. 4. Foi possível a adequação de 352 estacas com profundidade de 19 metros e diâmetro de 50 centímetros. $O$ distanciamento entre elas deveria ser de $1,50 \mathrm{~m}$, porém, para que fosse possível o encaixe dessas estacas no bloco de coroamento da fundação de forma equidistante e para não haver espaços vazios no bloco da estrutura da torre, foi necessária uma distância entre eixos maior que o aconselhado, resultando em 1,45m no eixo horizontal e $1,90 \mathrm{~m}$ no eixo vertical.

Figura 4 - Planta de fundação da estaca do tipo trado mecânico.

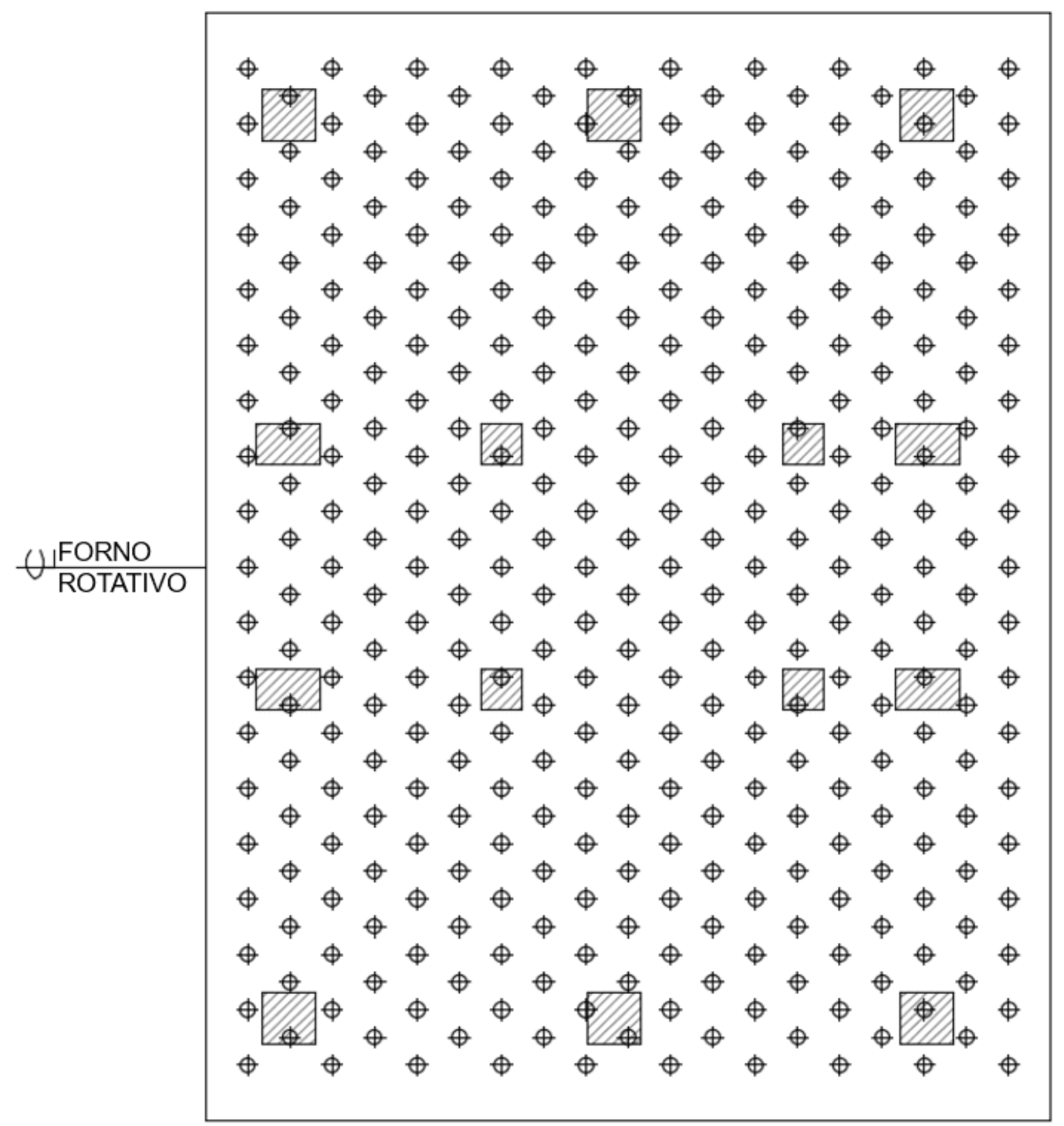

Fonte: O autor, 2019. 
O tipo de fundação que resultou em maior número de estacas foi do tipo Strauss, com diâmetro de 45 centímetros e profundidade também de 19 metros. Seguindo o mesmo método de determinação do distanciamento, seria necessária uma distância de 1,35m entre eixo das estacas. Entretanto, é a mesma situação abordada na estaca do tipo trado mecânico, o que acabou resultando em distâncias de $1,45 \mathrm{~m}$ no eixo horizontal e $1,70 \mathrm{~m}$ no eixo vertical, conforme FIG. 5 abaixo.

Figura 5 - Planta de fundação da estaca do tipo Strauss.

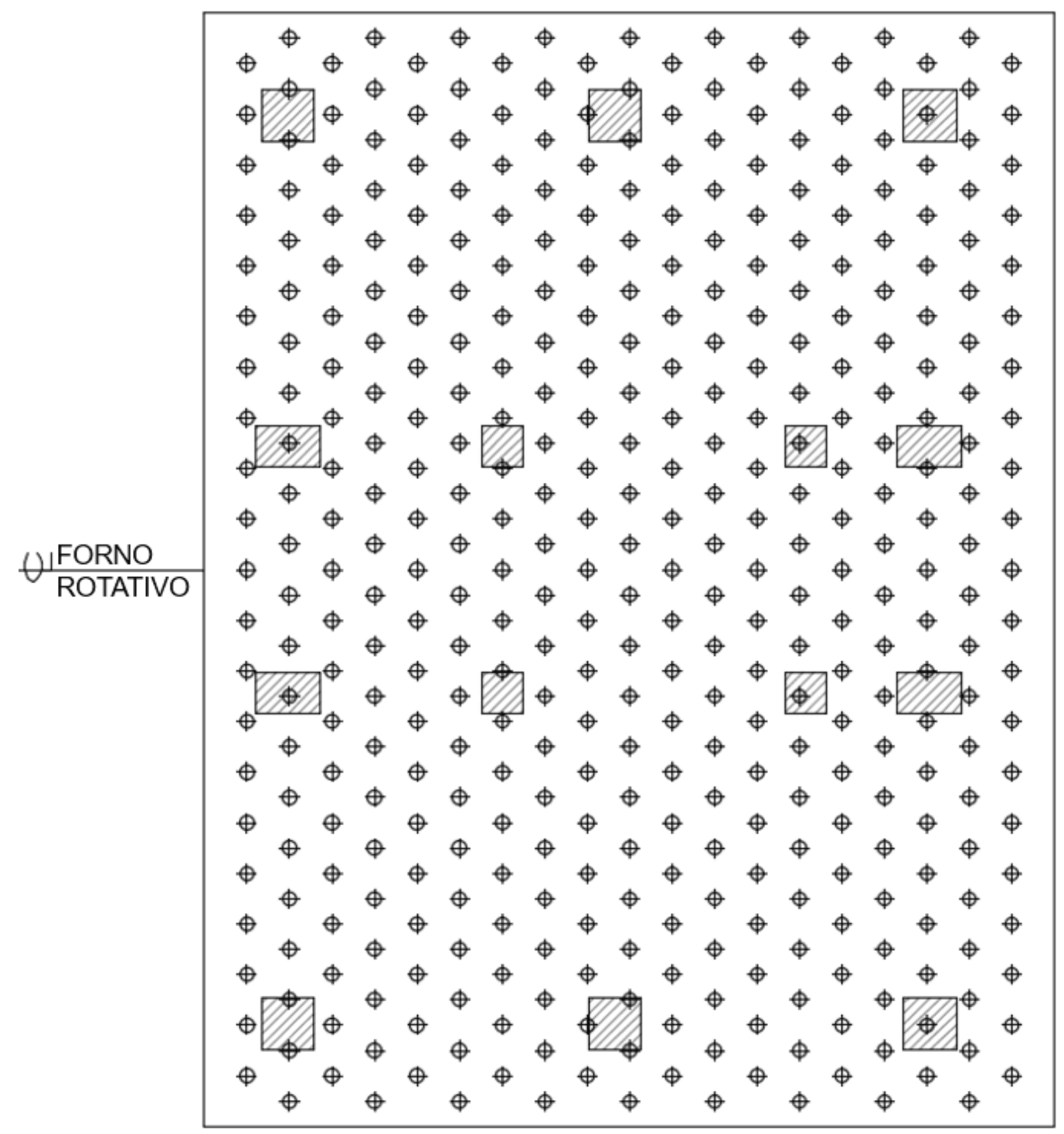

Fonte: O autor, 2019.

Disponível em: https://www.nucleodoconhecimento.com.br/engenharia-civil/alternativa-defundacao 
Considerando o número de estacas mediano, após a primeira análise para o trade-off, foi realizada a análise do volume de escavação de cada estaca, apresentado na TAB. 5.

Tabela - Volume de escavação de cada estaca.

\begin{tabular}{|l|l|l|l|l|}
\hline $\begin{array}{l}\text { TIPO DE } \\
\text { ESTACA }\end{array}$ & $\begin{array}{l}\text { DIÂMETRO } \\
(\mathrm{m})\end{array}$ & $\begin{array}{l}\text { PROFUNDIDADE } \\
(\mathrm{m})\end{array}$ & $\begin{array}{l}\text { MÉDIA №. } \\
\text { DE } \\
\text { ESTACAS }\end{array}$ & $\begin{array}{l}\text { VOLUME DE } \\
\text { ESCAVAÇÃO } \\
\left(\mathrm{m}^{3}\right)\end{array}$ \\
\hline $\begin{array}{l}\text { Hélice } \\
\text { contínua }\end{array}$ & 1,00 & 19 & 123 & 1.835 \\
\hline $\begin{array}{l}\text { Trado } \\
\text { mecânico }\end{array}$ & 0,50 & 19 & 343 & 1.279 \\
\hline \begin{tabular}{l} 
Strauss \\
\hline
\end{tabular} & 0,45 & 19 & 397 & 1.199 \\
\hline
\end{tabular}

Fonte: O autor, 2019.

Diante do volume de escavação, verifica-se uma diferença de $636 \mathrm{~m}^{3}$ da hélice contínua para a Strauss, equivalendo a quase $35 \%$ do volume maior de $1.835 \mathrm{~m}^{3}$. Após esta segunda análise tem-se o terceiro item a ser analisado, o volume de concreto estimado, conforme apresentado na TAB. 6, considerando uma porcentagem a mais, devido no caso da estaca Strauss haver o bulbo de pressão e na hélice contínua e trado mecânico uma taxa em consideração de perda no instante da concretagem.

Tabela - Volume de concreto das estacas.

\begin{tabular}{|l|l|l|l|l|}
\hline $\begin{array}{l}\text { TIPO DE } \\
\text { ESTACA }\end{array}$ & $\begin{array}{l}\text { DIÂMETRO } \\
(\mathrm{m})\end{array}$ & $\begin{array}{l}\text { PROFUNDIDADE } \\
(\mathrm{m})\end{array}$ & $\begin{array}{l}\text { MÉDIA №. } \\
\text { DE } \\
\text { ESTACAS }\end{array}$ & $\begin{array}{l}\text { VOLUME DE } \\
\text { CONCRETO } \\
\left(\mathrm{m}^{3}\right)\end{array}$ \\
\hline $\begin{array}{l}\text { Hélice } \\
\text { contínua }\end{array}$ & 1,00 & 19 & 123 & 1.651 \\
\hline
\end{tabular}

Disponível em: https://www.nucleodoconhecimento.com.br/engenharia-civil/alternativa-defundacao 


\begin{tabular}{|l|l|l|l|l|}
\hline $\begin{array}{l}\text { Trado } \\
\text { mecânico }\end{array}$ & 0,50 & 19 & 343 & 1.151 \\
\hline Strauss & 0,45 & 19 & 397 & 1.319 \\
\hline
\end{tabular}

Fonte: O autor, 2019.

Sendo assim, consta o comparativo entre o número de estacas, o volume de escavação e volume de concreto, apresentado no GRÁF. 2. É possível observar que há uma diferença considerável no número de estacas do tipo hélice contínua para as demais, caracterizada por diferenças que superam $100 \%$. Já para os volumes de escavação e concreto, a hélice contínua destaca com maiores quantidades, não maiores que $35 \%$ em relação aos valores dos outros dois tipos.

Gráfico - Resumo dos comparativos do trade-off da fundação da torre de précalcinação.

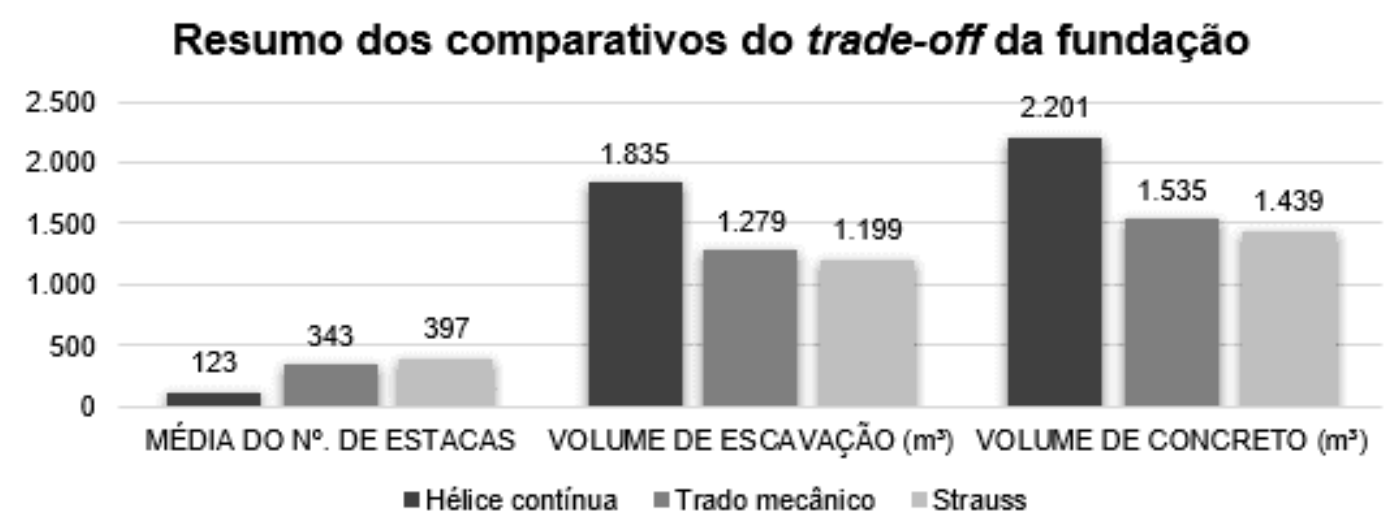

Fonte: O autor, 2019.

A estaca Strauss apresentou o menor volume de concreto e escavação, porém, foi a que apresentou o maior número de estacas. Segundo Gonçalves (2006) este é um método alternativo para edificações de pequeno e médio porte. A torre de précalcinação é uma obra de porte grande, o que já não seria interessante o uso deste tipo de estaca. Além disso, nota-se no SPT do local da edificação que há solo mole, e isto acaba sendo um fato que restringe o uso de estaca Strauss, pois pode haver dificuldades na furação, caso que se acontecesse, atrasaria toda a obra. Este tipo de

Disponível em: https://www.nucleodoconhecimento.com.br/engenharia-civil/alternativa-de- 
estaca, apesar de simples, tem a execução lenta. Portanto, este tipo de estaca não é tão viável à obra.

A estaca do tipo trado mecânico foi a que resultou em valores medianos e apresentou número de estacas mais próximos ao da estaca Strauss. Este tipo de estaca tem alguns limitantes como nível do lençol freático, solo muito mole, além de não apresentar uma boa produtividade, não sendo conveniente seu uso na fundação desta obra de grande porte, pois poderia haver muitas interferências que atrasariam todo o cronograma da obra.

O tipo de estaca que apresentou o maior volume de escavação e concreto foi a hélice contínua, a qual apresentou o menor número de estacas, justificando os volumes maiores pelo diâmetro desta ser o dobro dos outros tipos. A execução deste tipo de estaca é o mais rápido, pois a escavação do solo e injeção do concreto são realizadas simultaneamente, resultando em uma boa produtividade. Uma interferência que geraria impacto para este tipo de fundação seria a presença de matacão, porém, como no relatório de sondagem não foi indicado, não há restrições para o uso desta.

\section{CONCLUSÃO}

A importância de se obter resultados mais rápidos e assertivos evitando gastos desnecessários com retrabalhos de engenharia mostra a eficiência do trade-off, o qual aprimora o planejamento e ajuda na percepção de falhas no projeto ou até mesmo durante a obra ainda na engenharia preliminar. Com o trade-off da fundação da torre de pré-calcinação, chega-se à conclusão de que a estaca mais adequada para a estrutura é a do tipo hélice contínua que apesar de ter o destaque de maiores volumes de concreto e escavação, é a que tem menos estacas a serem executadas, e além disso este é o tipo mais eficiente quanto à produtividade em relação aos três tipos de fundação analisados, sendo assim, ganha-se tempo, e o tempo impacta no custo da obra, sendo esta a que apresenta o melhor custo benefício. Isso mostra a relevância do trade-off aplicado na construção civil, pois estas análises aprofundam mais no 
projeto e ampliam o lado crítico construtivo já pensando na execução e possíveis interferências/imprevistos, tendo consequentemente o êxito da obra.

\section{REFERÊNCIAS}

ALBUQUERQUE, R. C. B. L.; GUSMÃO, A. D. Considerações sobre a relevância da interação solo-estrutura em recalques: caso de um prédio na cidade do Recife. Escola Politécnica, Universidade de Pernambuco, Recife, 2006.

ASSOCIAÇÃO BRASILEIRA DE NORMAS TÉCNICAS. NBR 8036: Programação de sondagens de simples reconhecimento dos solos para fundações de edifícios. Rio de Janeiro, 1983.

BARBOSA, F. M. D. R.; CONCIANI, W. Estudo de caso: recalques diferenciais provocados por inundação do solo. XVIII Congresso Brasileiro de Mecânica dos Solos e Engenharia Geotécnica. COBRAMSEG 2016. 19-22 outubro. Belo Horizonte, Minas Gerais. ABMS, 2016.

GONÇALVES, R. F. Estudo do comportamento de estacas apiloadas em solo colapsível da região de Londrina/PR. Dissertação de pós-graduação em Engenharia de Edificações e Saneamento: Universidade Estadual de Londrina. Londrina, Paraná, 2006.

LOBO, B. D. Método de previsão de capacidade de carga de estacas: Aplicação dos conceitos de energia do ensaio SPT. Dissertação de mestrado. Porto Alegre, Rio Grande do Sul, Brasil: Universidade Federal do Rio Grande do Sul, 2005.

MARTIROSYAN, A. Z.; SOBOLEV, E. S. Safety of the execution of the foundation of the buildings and structures for dynamic implementation. National Research Moscow State University of Civil Engineering (NRU MGSU). Moscow. 2017.

MOREIRA, P. H. P. Gerenciamento de projetos: aplicação da teoria da tríplice restrição na escolha da opção mais viável para implantação de uma torre de pré- 
calcinação em uma indústria cimenteira localizada no centro-oeste mineiro. Trabalho de conclusão de curso. Centro Universitário de Formiga, Minas Gerais, 2017.

NANGAN II, A. P.; GANIRON JR, T. U.; MARTINEZ, D. T. Concrete foundation systems and footings. World Scientific News. WSN 80. 2017.

SANTOS FILHO, W. M.; ROMANEL, C.; NETO, S. F. S. Considerações a respeito dos fatores que influenciam no recalque e distribuição de cargas no grupo de estacas. Traços, Belém, v.3, no5, p. 33-38, jun, 2000.

SANTOS JOÃO, C. D. A. Pavimentos térreos industriais: aspetos relevantes ligados à conceção, dimensionamento e às tecnologias de execução. Dissertação de Mestrado. Faculdade de Engenharia da Universidade do Porto em Engenharia Civil. Portugal, 2014.

VELLOSO, D. de A.; LOPES F. de R. Fundações: Fundações Profundas. Nova Ed. São Paulo: Oficina de Textos, 2010.

Enviado: Agosto, 2019.

Aprovado: Outubro, 2019. 